\title{
Damage Assessment of Reinforced Concrete Elements Due to Corrosion Effect Using Dynamic Parameters: A Review
}

\author{
Ivan Duvnjak $^{1, * \mathbb{D}}$, Ivan Klepo ${ }^{2}$, Marijana Serdar ${ }^{1} \mathbb{D}$ and Domagoj Damjanović ${ }^{1} \mathbb{D}$ \\ 1 Faculty of Civil Engineering, University of Zagreb, 10000 Zagreb, Croatia; \\ marijana.serdar@grad.unizg.hr (M.S.); domagoj.damjanovic@grad.unizg.hr (D.D.) \\ 2 Croatia Control Ltd., 10410 Velika Gorica, Croatia; iklepo@gmail.com \\ * Correspondence: ivan.duvnjak@grad.unizg.hr
}

Citation: Duvnjak, I.; Klepo, I.; Serdar, M.; Damjanović, D. Damage Assessment of Reinforced Concrete Elements Due to Corrosion Effect Using Dynamic Parameters: A Review. Buildings 2021, 11, 425. https://doi.org/10.3390/ buildings 11100425

Academic Editor: Alessandra Aprile

Received: 29 July 2021

Accepted: 17 September 2021

Published: 22 September 2021

Publisher's Note: MDPI stays neutral with regard to jurisdictional claims in published maps and institutional affiliations.

Copyright: (C) 2021 by the authors Licensee MDPI, Basel, Switzerland. This article is an open access article distributed under the terms and conditions of the Creative Commons Attribution (CC BY) license (https:/ / creativecommons.org/licenses/by/ $4.0 /)$.

\begin{abstract}
Corrosion of reinforcement is one of the main problems related to the durability of reinforced concrete structures. This can cause cracks and a separation of the protective layer, as well as reducing strength and structural stiffness, which can result in numerous human casualties. Visual inspection is a standard method of assessing the condition of reinforced concrete structures whose limitations, such as time, interpretability, accessibility, etc., may affect its effectiveness. Therefore, damage determination methods based on dynamic parameters are becoming more and more prominent in the assessment of damage to reinforced concrete structures. The aim of this paper is to review the literature regarding the determination of corrosion of reinforcement by methods based on dynamic parameters, and to identify future research to develop a method that would detect corrosion problems in time through a continuous system of structural health monitoring.
\end{abstract}

Keywords: corrosion of reinforcement; structural dynamic parameters; reinforced concrete elements; damage detection

\section{Introduction}

In the last twenty years, there has been partial or complete collapse of over one hundred bridges located on frequent road and rail traffic routes in the world. Twenty-two bridges have collapsed in the last two years. In almost all of these bridges, the load-bearing structure collapsed while bearing regular traffic, and often during heavy traffic jams when the consequences of such collapses on human lives are immeasurably greater [1]. There are many factors that lead to the collapse of bridges, and they are generally divided into natural factors (floods, earthquakes, high-speed winds, landslides, etc.) and factors resulting from human actions (lack of proper maintenance or inspection of bridges) [2]. Also, over the past few decades there has been a significant increase in traffic and an increase in the weight of trucks, which is why bridges built in the mid-20th century, which are not dimensioned for such loads, are becoming critical parts of transport infrastructure [1]. Many studies and projects conducted in recent years have shown that the condition of load-bearing bridge structures in Europe, as well as around the world, is worrying [2-4]. Research conducted in several European countries through the BRIME project [4] has shown that $39 \%$ of bridges on French highways are damaged, while 3\% are at high risk of collapsing. Damage is also present on $37 \%$ of bridges in Germany (1.8\% in completely unsatisfactory condition), 30\% of bridges in the UK, and $26 \%$ of bridges in Norway. The most common damage that has occurred in all the bridges observed within the project were related to cracks and separation of the protective layer of concrete as a result of reinforcement corrosion [4]. In addition, 30\% of U.S. highway bridges were rated as deficient with recommended maintenance work [3].

Regular inspections and maintenance strategies for bridges were introduced only after several sudden collapses [3]. In the USA, mandatory inspection of bridges (once in a two year period) were introduced after the collapse of the Silver Bridge in 1967, in which 46 people lost their lives. Research conducted after the collapse concludes that the cause of 
the collapse was the failure of the steel bridge hanger due to the presence of corrosion damage [1]. With the collapse of the Seongsu Bridge in South Korea in 1994, which occurred due to the failure of a weld on one of the elements of the steel lattice structure, 32 people lost their lives [1], while in the collapse of the Sgt. Aubrey Cosens VS in Canada in 2003 there were no human casualties [3].

One of the last cases of collapse occurred in Italy in August 2018, on the busy A10 traffic route connecting the seaport of Genoa with the rest of Europe (Figure 1).

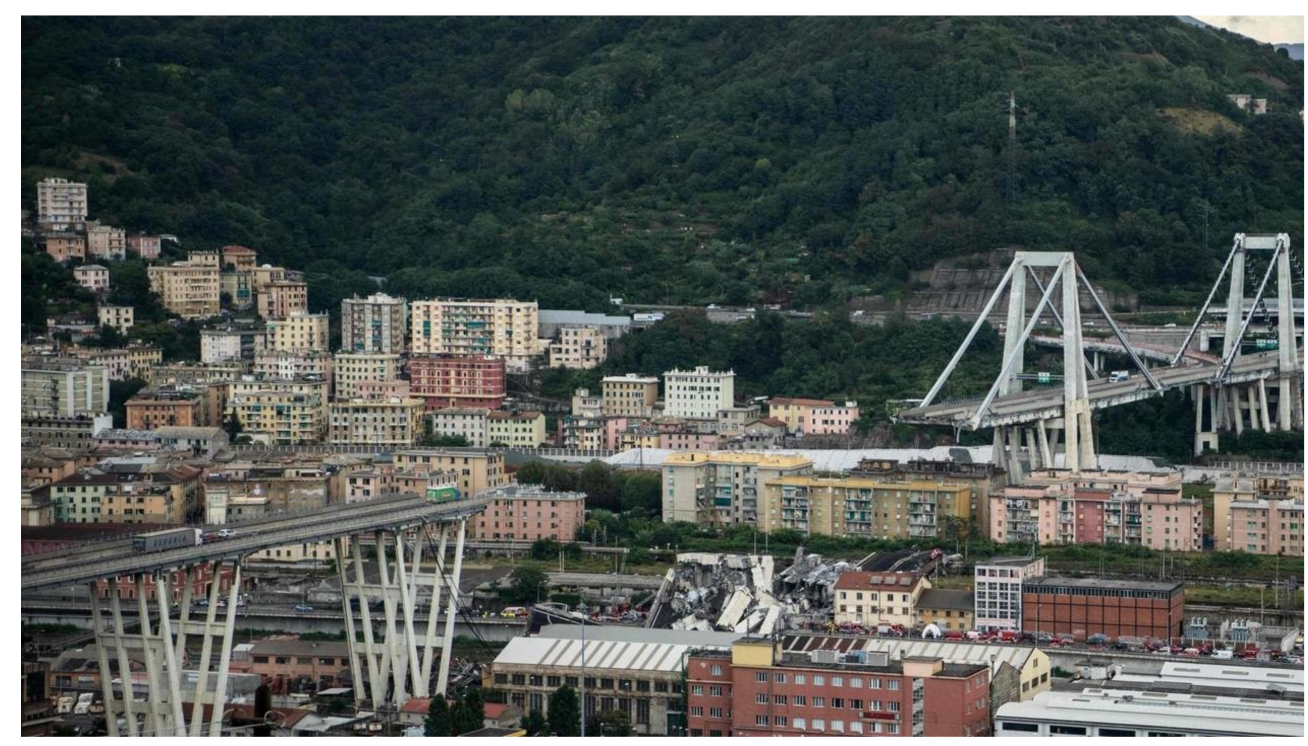

Figure 1. View of the collapsed part of the Polcever viaduct in Genoa, August 2018. (AP Photo, Antonio Calanni, 2018).

As a result of the collapse of part of the Polcever viaduct, built in 1967 according to a project by Riccardo Morandi, forty-three people were killed that day. The viaduct is $2.4 \mathrm{~km}$ away from the sea, so it was directly exposed to the aggressive action of seawater salt throughout its use. Analysis concluded that the failure of the hanger, made of prestressed concrete, was due to a combination of fatigue of the material and damage caused by corrosion, whose progressiveness was high due to the proximity of the sea and the industrial zone [5]. In order to minimize such catastrophic events in the future, it is necessary to emphasize detailed assessments of the condition of existing bridge structures and apply appropriate modern maintenance measures, or consider the removal of those that are not worth repairing [6].

The impact of reinforcement corrosion is one of the most significant problems related to the durability of concrete structures [7]. Corrosion of reinforced concrete elements is always a coupling phenomenon between steel cross section reduction and loss of bond strength [8]. Either uniform or local corrosion can have important effects on the mechanical behavior of the steel reinforcement bars [9] and has previously led to a decrease in the strength and stiffness of reinforced concrete structures [10]. The consequent action of corrosion causes initial cracks in the concrete and separation of the protective layer (Figure 2). 


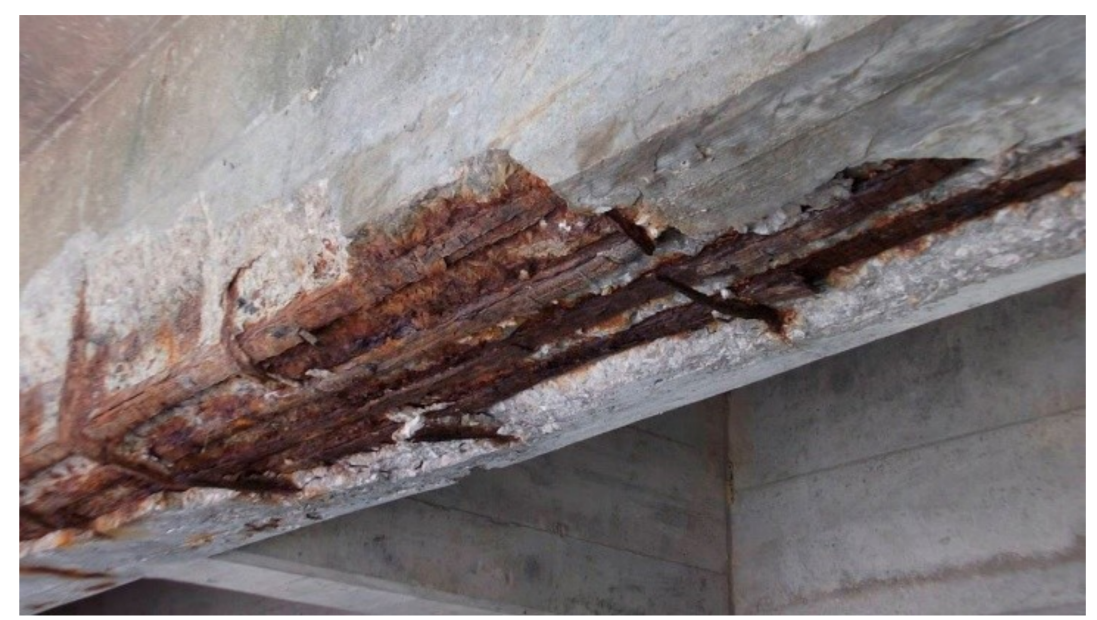

Figure 2. Display of reinforcement corrosion effects in reinforced concrete beam.

In prestressed concrete structures, corrosion of prestressing strands at early stages results in microcracking, deterioration of the bond between strands and concrete, and therefore, in the loss of prestressing force. In an advanced stage, corrosion may result in the rupture of strands [11,12].

The traditional method for assessing the condition of reinforced concrete structures is visual inspection [13]. However, this method has several limitations such as the difficulty of accessing locations of damage on the structure. Likewise, the location of damage needs to be known in advance and the application process itself is time consuming and prone to human error due to subjective data analysis [14]. Furthermore, before the appearance of cracks, the corrosion process cannot be detected by visual inspection.

In addition to visual inspections, for assessing the condition of reinforced concrete structures it is possible to determine corrosion parameters by any of the electrochemical methods [15]. However, such measurements generally cover a smaller test area, and localized information is obtained on the condition of the reinforcement in the concrete. Also, these methods are not applicable to prestressed concrete due to the impossibility of an electrical connection with prestressed cables. Due to all of the above, the methods for damage detection based on the change of dynamic parameters are becoming increasingly important in the assessment of reinforced concrete structures [16].

The aim of this paper is to give a comprehensive review of literature regarding the determination of the degree of corrosion of reinforcement and consequent reduction of stiffness using methods based on dynamic parameters. The following is an overview of damage determination methods based on changes in dynamic parameters.

\section{Damage Detection Methods Using Change of Dynamic Parameters}

The most common damage detection methods are based on the change of the structural dynamic parameters which are function of stiffness, mass, or energy dissipation of the structure. Damage of structure leads to alteration of dynamic parameters [17]. The main goal of such methods is to detect damage at the earliest possible stage in order to avoid sudden collapses of structures, as well as the possible prediction of the remaining life of structures $[18,19]$. The damage detection process (Figure 3) consists of determining the existence of damage (level 1), the location of damage (level 2), the level of damage (level 3), and predicting the remaining life of the structure (level 4) [20]. Extensive reviews of damage detection methods based on the changes of different dynamic parameters are given in $[16-19,21,22]$. In the following chapters the most widespread methods for structural damage detection based on the change of structural dynamic parameters are given. In the opinion of the authors those methods have a great potential for application in the damage assessment of reinforced concrete structures due to corrosion. 


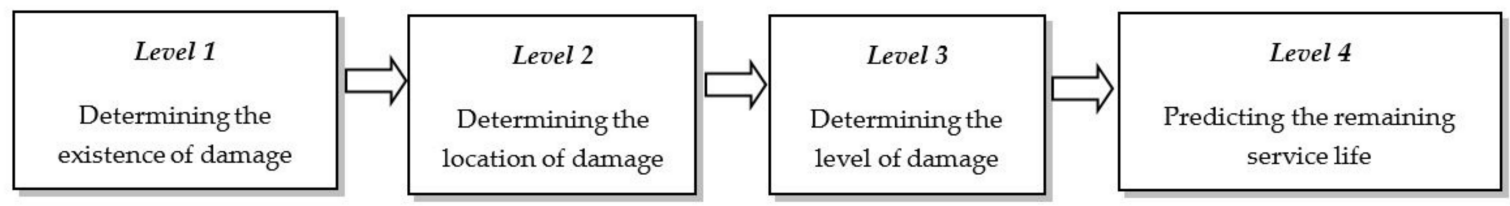

Figure 3. Demonstration of the damage determination system according to [20].

\subsection{Changing of Natural Frequencies}

The appearance of damage on the observed structure leads to a decrease in the stiffness of the structure, which results in a decrease in the value of the natural frequency $[22,23]$. The idea of applying natural frequencies for damage detection was proposed in the 1970s [24]. Given the ease of application, accuracy in determining, and sensitivity to changes in the global stiffness of the structure, this method is one of the most commonly used methods in determining the existence of damage [25]. However, by applying only the natural frequencies, it is very difficult to determine the location of the damage [22]. Also, in the presence of symmetrical damage to the structure, it is not possible to distinguish from the change of natural frequencies what exactly the damage is [26]. The global influence of damage on the structural stiffness can be represented by the natural frequency ratio [27]:

$$
\delta_{i}=\frac{\left(f_{i}^{*}-f_{i}\right)}{f} \times 100[\%]
$$

where $\delta_{i}$ represents the index of change of the natural frequency for the $i$-th mode shape, $f_{i}$ the frequency of the $i$-th mode shape in the undamaged state, and $f_{i}^{*}$ the frequency of the $i$-th mode shape in the damaged state. If we observe a larger number of natural frequencies, their arithmetic mean can be calculated [27]:

$$
\bar{\delta}_{i}=\frac{1}{n} \sum_{i=1}^{n} \delta_{i}
$$

where $\bar{\delta}_{i}$ represents the change index of all natural frequencies for $\mathrm{n}$ mode shapes.

From the above literature review, it can be stated that the change of natural frequencies is a reliable indicator in damage detection and very useful in regular inspections of structures.

\subsection{Modal Damping Change}

Modal damping was considered as a parameter that could be sensitive to the existence of damage due to the assumption that the appearance of cracks in the cross section causes an increase in internal friction resulting in an increase in the damping value [28]. The advantage of using a change in modal attenuation over a change in natural frequencies is the ability to detect the nonlinear effect of smeared cracks on the structure [29]. Despite the relatively small damage present on the observed structures authors in their studies $[20,30]$ showed that the change in damping due to this small damage was nevertheless significant.

The analysis of the change in the damping coefficient $(\Delta \xi)$ is based on a comparison of the damping coefficient before and after the damage to the structure [31]:

$$
\Delta \xi_{i}=\frac{\xi_{i}^{*}-\xi_{i}}{\xi_{i}} \times 100[\%]
$$

where $\xi_{i}$ and $\xi_{i}{ }^{*}$ are the damping coefficients of the undamaged and damaged structure for the $i$-th modal shape, respectively.

Since damping is very sensitive to certain influences such as temperature and load history, its change is a reliable parameter for damage detection on simple structures and in a controlled environment [32]. Also, as the modal damping change may depend on the 
type of load, it is very important to determine the expected damages in order to avoid confusion in the interpretation of the results [33].

\subsection{Change of Mode Shapes-MAC, COMAC}

The mode shape, as a form of oscillation of the structure at the appropriate frequency, also changes due to the occurrence of damage to the structure [34,35]. The change in mode shapes is less dependent on external influences (temperature) than natural frequencies and can be used to determine one or more damage locations (Figure 3, level 2) [36]. Unlike determining natural frequencies, determining mode shapes is much more complex and requires a large number of sensors.

For the direct change of the modal shape between the undamaged and damaged state of the structure, the criterion of modal orthogonality (MAC) is most often used. MAC was first used in 1984 for the purpose of determining the location of damage without using the finite element model [37]. It gives the degree of correlation between the undamaged and damaged state and varies between 0 and 1 [38]. If the value of the MAC factor is equal to 1 , it is an ideal overlap of two mode shapes, i.e., no damage. The formula for calculating MAC factor values is as follows:

$$
\operatorname{MAC}_{(i, j)}=\frac{\left(\left\{\phi^{A}\right\}_{i}^{T}\left\{\phi^{B}\right\}_{k}\right)^{2}}{\left(\left\{\phi^{A}\right\}_{i}^{T}\left\{\phi^{A}\right\}_{i}\right)\left(\left\{\phi^{B}\right\}_{k}^{T}\left\{\phi^{B}\right\}_{k}\right)}
$$

where $\left\{\phi^{A}\right\}_{i}$ is the normalized $i$-th mode shape vector for the undamaged state and $\left\{\phi^{B}\right\}_{k}$ is the normalized $k$-th mode shape vector for the damaged state of the structure.

Kim et al. [39] advanced the MAC criterion to the coordinate modal assurance criterion, COMAC. This criterion uses modal node displacements to directly determine and localize damage and takes into account the total number of mode shapes $n$ [40]:

$$
\operatorname{COMAC}_{j}=\frac{\sum_{i=1}^{n}\left[\phi_{A i}^{j} \phi_{B i}^{j}\right]^{2}}{\sum_{i=1}^{n}\left[\phi_{A i}^{j} \phi_{A i}^{j}\right] \sum_{i=1}^{n}\left[\phi_{B i}^{j} \phi_{B i}^{j}\right]}
$$

where $\phi_{A i}^{j}$ and $\phi_{B i}^{j}$ modal components are for the $i$-th modal shape for the measuring point $j$, and two pairs of modal shapes. When COMAC is equal to zero then it is a possible location of the damage.

\subsection{Mode Shape Curvature Method}

Another way of using modal shapes in determining damage is to use their other derivations, i.e., the mode shape curvature. The appearance of cracks reduces the rigidity of the structure and increases the curvature. The concept of damage detection using mode shape curvature was introduced by Pandey et al. [41]. They show that in certain situations it is more effective than damage detection using mode shape changes. Maeck and De Roeck [42] used mode shape curvature changes to detect damage on a bridge. Approximation by central difference is the simplest way to calculate the modal curvature [43]:

$$
w^{\prime \prime}=\frac{\left(w_{i+1}-2 w_{i}+w_{i-1}\right)}{h^{2}}
$$

where the $w$ vector is of modal shape, and $h$ is the distance between the two measured locations (i).

Wahab and De Roeck [39] also developed a modal curvature damage factor (CDF) which represents the difference in modal curvature between an undamaged and a damaged structure:

$$
C D F=\frac{1}{n} \sum_{i=1}^{n}\left|w_{u i}^{\prime \prime}-w_{d i}^{\prime \prime}\right|
$$


where $n$ is the total number of modal shapes, $w_{u i}^{\prime \prime}$ the curvature of the modal shape of the undamaged structure, and $w_{d i}^{\prime \prime}$ the curvature of the modal shape of the damaged structure.

Ho and Ewins [44] improved this method by developing a method of quadratic modal curvature that amplifies changes in curvature, and thus more easily detects abnormal changes. In addition to these advantages, the method of modal curvature has certain disadvantages related to the large number of measurement points required to determine higher modes, which decrease the efficiency of the method [45].

\subsection{Changing the Modal Flexibility}

The application of modal flexibility for structural damage detection was proposed by Pandey and Biswas [46], while Toksoy and Aktan [47] first used it to determine damage to bridges. The advantage of this method is that the flexibility matrix, which is inverse to the stiffness matrix, can be determined directly from experimental research, without the need to develop an analytical model of the structure [46]. Therefore, this method is often present in the monitoring of building structures, and its use has been observed in combination with the mode shape curvature method [48].

From the equation of free undamped oscillations, the flexibility matrix is obtained as the reciprocal value of the stiffness matrix [49]:

$$
[F]=[\phi]\left[\frac{1}{\omega^{2}}\right][\phi]^{T}
$$

where $[\phi]$ is the normalized mode shape, and $\omega_{i}$ is the natural frequency of the $i$-th mode shape.

Modal flexibility at a given location on a structure $x\left(F_{x}\right)$ is calculated as:

$$
F_{x}=\sum_{i=1}^{n} \frac{1}{\omega_{i}^{2}} \phi_{x i} \phi_{x i}^{T}
$$

where $i(i=1,2,3 \ldots \mathrm{n})$ represents the number of a certain mode shape, $n$ the total number of mode shapes, and $\omega_{i}$ the natural frequency of the $i$-th mode shape.

The change in flexibility between the damaged and undamaged structure is obtained as:

$$
[\Delta F]=[F]-\left[F^{*}\right]
$$

This method is often applied with very good results, except in the case of multiple damages, an exception which is also the biggest drawback of this method.

\subsection{Discussion}

Systematization in the form of advantages and disadvantages of the previously mentioned damage detection methods based on the structural dynamic parameters is shown in Table 1. 
Table 1. Overview of advantages and disadvantages of damage detection.

\begin{tabular}{|c|c|c|}
\hline $\begin{array}{c}\text { Damage Determination } \\
\text { Method }\end{array}$ & Advantages & Disadvantages \\
\hline $\begin{array}{l}\text { Changing of natural } \\
\text { frequencies }\end{array}$ & $\begin{array}{l}\text {-the ability to easily measure the natural } \\
\text { frequency with high accuracy } \\
\text {-sensitivity on structural stiffness changes } \\
\text {-expected variations of natural frequency can } \\
\text { be successfully monitored through the } \\
\text { structural health monitoring system } \\
\text {-applicable for detection damage existence } \\
\text { (Figure 2, level 1) }\end{array}$ & $\begin{array}{l}\text {-impossibility to determine the damage location } \\
\text { (global parameter) } \\
\text {-sensitivity to environmental effects (temperature } \\
\text { change) } \\
\text {-difficult to determine the position of the load in } \\
\text { symmetrical damages }\end{array}$ \\
\hline Modal damping change & $\begin{array}{l}\text {-the possibility of detecting a nonlinear effect } \\
\text { from smeared cracks on the structure } \\
\text {-an alternative method in case the natural } \\
\text { frequencies and mode shapes are not } \\
\text { sufficiently sensitive and reliable } \\
\text {-applicable for detection of the damage } \\
\text { existence (Figure 2, level 1) }\end{array}$ & $\begin{array}{c}\text {-sensitivity to temperature, load history, etc. } \\
\text {-reliability only for simple structures } \\
\text {-very complex methods for use in practical } \\
\text { application }\end{array}$ \\
\hline Changing mode shapes & $\begin{array}{l}\text {-greater sensitivity in determining the location } \\
\text { of damage than natural frequencies } \\
\text {-application is possible at level } 2\end{array}$ & $\begin{array}{c}\text {-requires a large number of sensors } \\
\text {-sensitivity to environmental effects during } \\
\text { measurement } \\
\text {-depends on the completeness of the measured } \\
\text { degrees of freedom } \\
\text {-weakly sensitive method to small change in stiffness }\end{array}$ \\
\hline $\begin{array}{c}\text { Changing the curvature } \\
\text { of mode shapes }\end{array}$ & $\begin{array}{l}\text {-accuracy in determining the location of } \\
\text { damage } \\
\text {-only experimental data are sufficient } \\
\text {-proven reliability on real construction (bridge) }\end{array}$ & $\begin{array}{c}\text {-less sensitive to multiple damages } \\
\text {-the need for a large number of sensors } \\
\text {-efficiency depends on the number of considered } \\
\text { modes shapes }\end{array}$ \\
\hline $\begin{array}{l}\text { Changing modal } \\
\text { flexibility }\end{array}$ & $\begin{array}{l}\text {-direct determination of the flexibility matrix } \\
\text { from experimental research } \\
\text {-sufficient reliability with the use of only the } \\
\text { first few modal forms in the calculation } \\
\text {-much more sensitive than mode shapes and } \\
\text { natural frequencies }\end{array}$ & $\begin{array}{c}\text {-unreliability in determining the locations of } \\
\text { multiple damages } \\
\text {-requires a large number of sensors for more accurate } \\
\text { determination of modal shapes }\end{array}$ \\
\hline
\end{tabular}

\section{Determination of Corrosion on Reinforced Concrete Elements Using Vibration-Based Methods-A Review}

This research was conducted in order to define the current state of the art in terms of determining corrosion damage on reinforced concrete elements using vibration-based methods, as well as to investigate the possibilities and limitations of such methods. The results of this research may be the first step in defining the area of further research, which may be useful to both scientists and practitioners. The literature review includes scientific articles published to date that are related to the issue of the effectiveness of changes in dynamic parameters (natural frequencies, modal shapes, and modal damping) in the assessment of damage caused by corrosion, which is consistent with the aim of this study. Figure 4 schematically shows dynamic testing of the reinforced concrete beam, and the process of artificially inducing corrosion of reinforcement in $5 \% \mathrm{NaCl}$ solution that is the most commonly used procedure in processed scientific articles. 


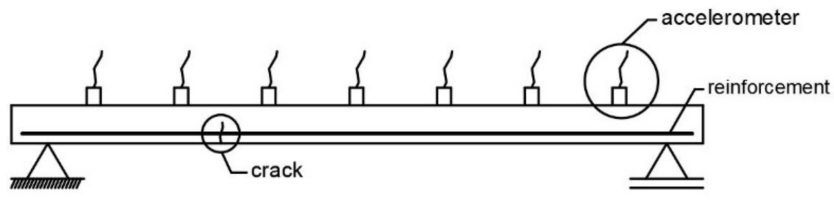

(a)

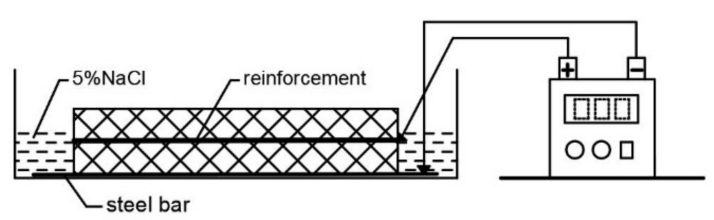

(b)

Figure 4. (a) Schematic representation of dynamic tests of reinforced concrete beam and (b) procedure of artificial induction of reinforcement corrosion.

\subsection{Research Review and Result Analysis}

J. Wu and S.X. Wu [10] presented a method of locating damage caused by corrosion on reinforced concrete elements. Their method is based on modal analysis, using the ratio of squares of frequency change as a parameter theoretically confirmed to be a function of the location of damage caused by corrosion, and whose minimum value suggests a damaged element. Field and laboratory experiments were performed on a total of five corroded reinforced concrete fence elements of the western part of Lian Yun Harbor, with cross section dimensions of $50 \mathrm{~mm} \times 80 \mathrm{~mm}$, and length of $880 \mathrm{~mm}$ [10]. J. Wu and S.X. $\mathrm{Wu}$ concluded that the ration of the square of the change in frequency can be used as a parameter to determine the location of damage caused by corrosion. The results obtained in the field match those from the laboratory, with the note that errors in measurements and models have significant impact on the accuracy of results and therefore should be kept as minimal as possible.

R. Capozucca [50] experimentally tested three prestressed reinforced concrete beams (B0, B1 and B2) in which they determined the degree of damage due to corrosion of reinforcement caused by artificial electrochemical process. The dimensions of the double $\mathrm{T}$ cross-section of the beams were $100 \mathrm{~mm} \times 130 \mathrm{~mm} \times 30 \mathrm{~mm}$, and the length $1=2.45 \mathrm{~m}$. Beam B0 was tested for bending to fracture, while beams B1 and B2 were gradually loaded and dynamically tested at certain load levels, provided that the beam B2 was exposed to artificial corrosion through three cycles lasting three months. The experimental dynamic analysis applied to beams B1 and B2 aimed to determine the damage caused by corrosion in its initial stage without the presence of cracks, as well as at different degrees of bending load [50].

R. Capozucca [50] concluded that the corrosion process did not significantly affect the change of natural frequency and dynamic response of a beam in cases where beams were not exposed to bending loads. Based on this he also concluded that the corrosion process in the absence of cracks in concrete does not significantly affect the dynamic response of the beam. In the case of beams loaded with bending, the decrease in the value of frequencies at certain load stages is greater in beams that have been exposed to artificially induced corrosion, as shown in Figure 5 [50].

In the article [51] it was found that the changes of modal damping in uniform corrosion can range from $28 \%$ to $59 \%$. In the case of local corrosion in [51], the phenomenon was observed that with each repeated dynamic test the obtained dynamic parameters had different values, which may be due to unstable surface cracks whose characteristics changed with each application of force. The values of the natural frequencies decreased until the third repetition after which they had stable values, while the values of the modal attenuation coefficients increased until the fourth repetition after which they began to decrease.

L. Zuccarino et al. [52] studied the sensitivity and identification of modal parameters in the presence of corrosion damage. Their research was conducted on 3 different groups (T1, T4 and T7) of prestressed beams of identical cross-sectional dimensions and length in the amount of $\mathrm{L}=320 \mathrm{~cm}$. In each group there were five beams, one of which was preserved as undamaged, while the others were with different levels of corrosion, which represented a loss of steel surface in the amount of 3, 5, 6, 10, 12, 15 and $30 \%$. The corrosion 
process was artificially induced and accelerated and was applied exclusively to the central part of the beam in the length of $192 \mathrm{~cm}\left(\mathrm{~L}_{\mathrm{c}}=0.6 \mathrm{~L}\right)$, which represents almost uniform corrosion [52].

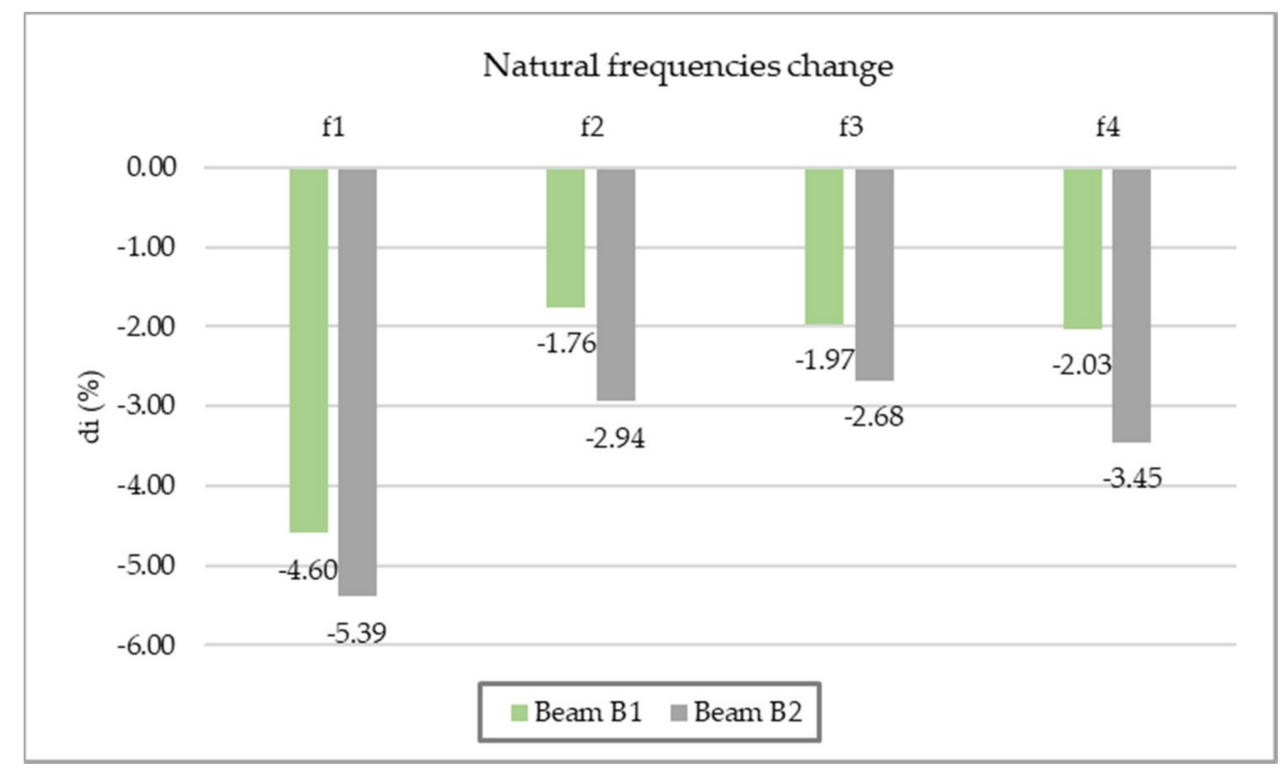

Figure 5. Representation of the change in the values of the natural frequencies for beams B1 (uncorroded) and B2 (corroded) (author's processing based on [46]).

The positive maximum value of the natural frequency change in the article [52] is a consequence of the increase of the natural frequencies of higher modal forms which, as shown in the article, are less sensitive to the presence of reinforcement corrosion than the lower modal forms. It was also observed that the change in the frequency of the third mode shape at a corrosion level of $10 \%$ is approximately $1 \%$, which is considered the limit value for determining damage present due to errors in experimental measurements. As part of the presentation of the results of the article [52], the experimentally determined mode shapes of the undamaged structure were compared with the experimentally determined mode shapes of the structure on which the corrosion of the reinforcement was artificially induced. The obtained values of the MAC criteria were above 0.95 , which implies the concordance of mode shapes and the possibility of their use to determine damage caused by corrosion, although in this case it is almost uniform corrosion which is certainly less suitable than local corrosion to determine damage to modal shapes. During examination of the obtained values of modal damping in beams with reinforcement corrosion, their growth in relation to the undamaged condition was observed which is greater than the uncertainty interval and as such applicable to determine the damage caused by corrosion, and more sensitive than determining the natural frequency damage. The research also concluded that a corrosion level of $15 \%$ results in a loss of structural stiffness of 5\% [52].

H.A. Razak and F.C. Choi [53] examined three reinforced concrete beams to establish the relationship between the degree of damage caused by corrosion and the change in natural frequencies and modal damping. Two beams were exposed to different levels of corrosion (D1 and D3), while the third served as a control beam (C). The loss of steel surface in both beams was less than $8 \%$ and $7.77 \%$ in beam D1, where the maximum crack width was $5.0 \mathrm{~mm}$ and $7.65 \%$ in beam D3 with a maximum crack width of $1.0 \mathrm{~mm}$ [53].

H.A. Razak and F.C. Choi [53] concluded that, due to corrosion damage, the D1 beam had a decrease in natural frequencies in the range of $4 \%$ to $11 \%$, while the D3 beam had a decrease between $1 \%$ and $4 \%$ (Figure 6). Also, with the beam D1, a larger decrease in bending stiffness was observed, as well as a smaller bearing capacity than with the beam D3. From the damping coefficients determined for the first three modal forms, their increase was observed in the second and third modal forms, while in the first modal form there was a 
decrease in the values of damping coefficients; this is explained by a stronger bond between steel and concrete in corroded reinforced concrete elements due to accumulated corrosion products (Figure 7). The above research results show that the decrease in the value of natural frequencies and the decrease in the value of bending stiffness, i.e., the increase in the value of the damping coefficients is greater the more damaged the sample [53].

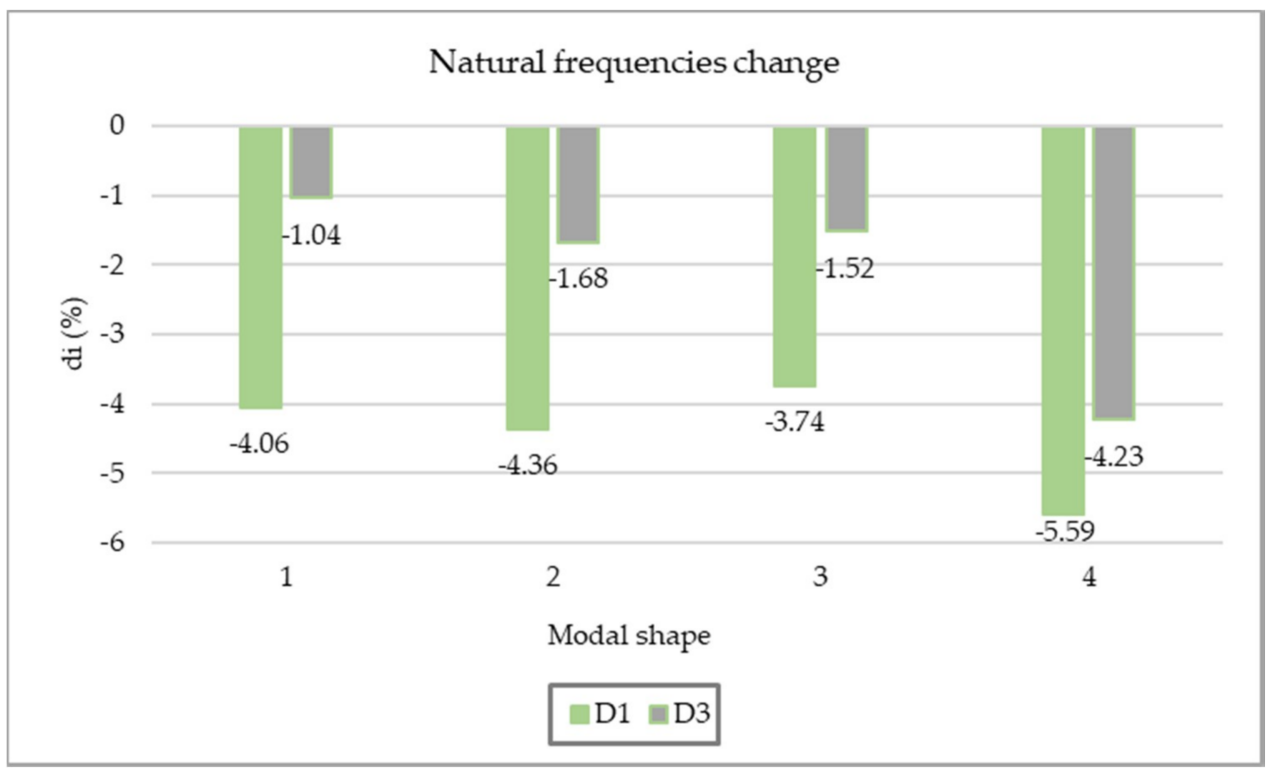

Figure 6. Representation of the change in the values of natural frequencies on beams D1 (steel surface loss $7.77 \%$, maximum crack width $5.0 \mathrm{~mm}$ ) and D3 (steel surface loss $7.65 \%$, maximum crack width $1.0 \mathrm{~mm}$ ) (author's processing based on [53]).

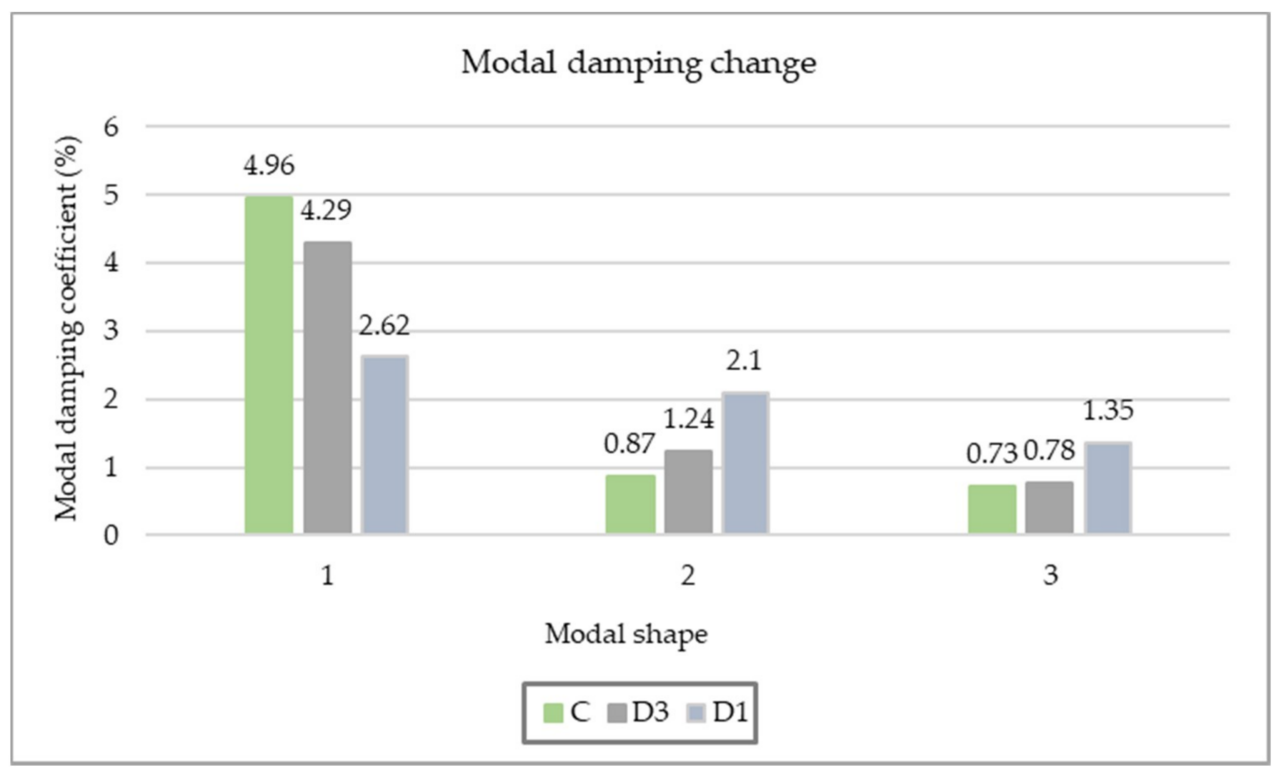

Figure 7. Change of damping coefficient value on beams $C$ (control beam), D1 (steel surface loss $7.77 \%$, maximum crack width $5.0 \mathrm{~mm}$ ) and D3 (steel surface loss $7.65 \%$, maximum crack width $1.0 \mathrm{~mm}$ ) (author processing based on [53]).

N.F. Ortega and S.I. Robles [54] developed an experimental-numerical methodology for estimating the remaining service life of structures with damage caused by corrosion of reinforcement. Twelve reinforced concrete beams, dimensions $8 \times 16 \times 110 \mathrm{~cm}$, exposed to accelerated corrosion on the central part of the beam $50 \mathrm{~cm}$ long, with different types 
of concrete designed to have properties similar to those of concrete from structures in use [54]. Dynamic tests determined a decrease in the first natural frequency between $9 \%$ and $17 \%$, with a maximum loss of the cross-sectional area of the longitudinal reinforcement in the amount of $16 \%$. The most important aspect of the presented methodology refers to the possibility of timely decisions on remediation or removal of the structure in question, depending on the obtained value of the remaining working life of the structure, which is proposed in mathematical form and based on the results of dynamic tests [54].

D.J. Zou et al. [55] experimentally tested three prefabricated reinforced concrete frames and two pillars, on which they caused corrosion of the reinforcement by electrochemical process, except for one frame which served as a control frame. This was followed by dynamic tests of corrosion-damaged frames and pillars to determine the influence of each level of corrosion on the values of natural frequencies and damping coefficients. The three states of the load-bearing structure of the frame simulated during the test were undamaged $(\mathrm{H})$, a state with $10 \%$ weight loss of steel (SC10) and a state with $30 \%$ weight loss of steel (SC30) [55]. The results showed a significant increase in natural frequency in corrosion-damaged frames $(\mathrm{H}-25 \mathrm{~Hz}, \mathrm{SC} 10-31 \mathrm{~Hz}, \mathrm{SC} 30-29 \mathrm{~Hz})$, with a maximum width of longitudinal cracks in the amount of $1.0 \mathrm{~mm}$ (SC10) and $2.0 \mathrm{~mm}$ (SC30). From the above results, it can be concluded that the stiffness of the corroded reinforced concrete element at low load, with reduced bond strength between steel and concrete, and reduced load-bearing capacity, may be higher than the stiffness of the undamaged element. It was also concluded from further test results that due to corrosion of reinforcement there is an increase in the values of damping coefficients, i.e., that the structural system has the highest energy dissipation capacity when the degree of corrosion damage (loss of steel mass) is between $14 \%$ and $35 \%$. By further increasing the degree of corrosion and degradation of the structure, large cracks are created, resulting in a loss of energy dissipation ability [51].

D.C. Hettiarachchi et al. [56] investigated changes in the modal parameters of reinforced concrete beams due to corrosion of reinforcing bars, with emphasis on changes in modal damping as corrosion damage progresses. For the purposes of the experiment, three identical reinforced concrete beams marked Tr-1, Tr-2 and Tr-3, dimensions $100 \mathrm{~mm}$ $\times 70 \mathrm{~mm} \times 880 \mathrm{~mm}$, with built-in reinforcement bars with a diameter of $10 \mathrm{~mm}$ and a reinforcement coefficient of $4.4 \%$ (two bars per sample), and a protective layer $30 \mathrm{~mm}$ thick. The samples were subjected to an electrochemical process (accelerated corrosion test) which caused artificial local corrosion in the central part of the beam length of 100 $\mathrm{mm}$. This was done in such a way that a current of $200 \mathrm{~mA}$ (equivalent to a current density of $3000 \mu \mathrm{A} / \mathrm{cm}^{2}$ ) was applied between the steel reinforcement (anode) and copper sheet measuring $200 \mathrm{~mm} \times 100 \mathrm{~mm} \times 5 \mathrm{~mm}$ (cathode) located under a piece of spongy material which facilitated the flow of current, since the reinforced concrete sample was placed directly outside the $3 \% \mathrm{NaCl}$ solution (electrolyte). Local corrosion is considered for the reason that it is more similar to damage in real structures than continuous corrosion. Three accelerated corrosion procedures were performed on the Tr-2 sample, while a series of fifteen procedures was performed on the Tr-3 sample. After the completion of each procedure, a dynamic test of samples simply supported at both ends was performed [56].

By examining the Tr- 2 and Tr-3 samples in article [56], the change in the values of the natural frequency and damping coefficients at different degrees of local corrosion was monitored. As part of the Tr-2 sample test, dynamic tests were performed at three different degrees of corrosion (L-1, L-2, and L-3). In the third stage (L-3) there was a decrease in the value of natural frequencies in the amount of $33.17 \%$ compared with the undamaged state, while the value of the attenuation coefficient was 7.68 times higher. In the Tr-3 sample, dynamic tests were performed after each of the fifteen accelerated corrosion tests and changes in the values of the natural frequency and damping coefficients were monitored during each test, as was the achieved degree of corrosion. The degree of corrosion in this case is shown as the product of the current strength expressed in milliamperes $(\mathrm{mA})$ and the duration of each corrosion process expressed in seconds (s). The test results show that a significant decrease in the value of the natural frequency, i.e., an increase in the value 
of the damping coefficient, occurred after the tenth accelerated corrosion procedure (at a corrosion rate of $9720 \mathrm{~A} \times \mathrm{s}$ ), which is explained by the appearance of a crack at the bottom of the sample just before the tenth procedure (Figure 8). Dynamic tests after the last series of fifteen procedures showed a decrease in the value of the natural frequency in the amount of $5.8 \%$, and an increase in the value of the damping coefficient in the amount of $117 \%$, demonstrating that changes in the damping value are more sensitive to damage caused by corrosion [56].

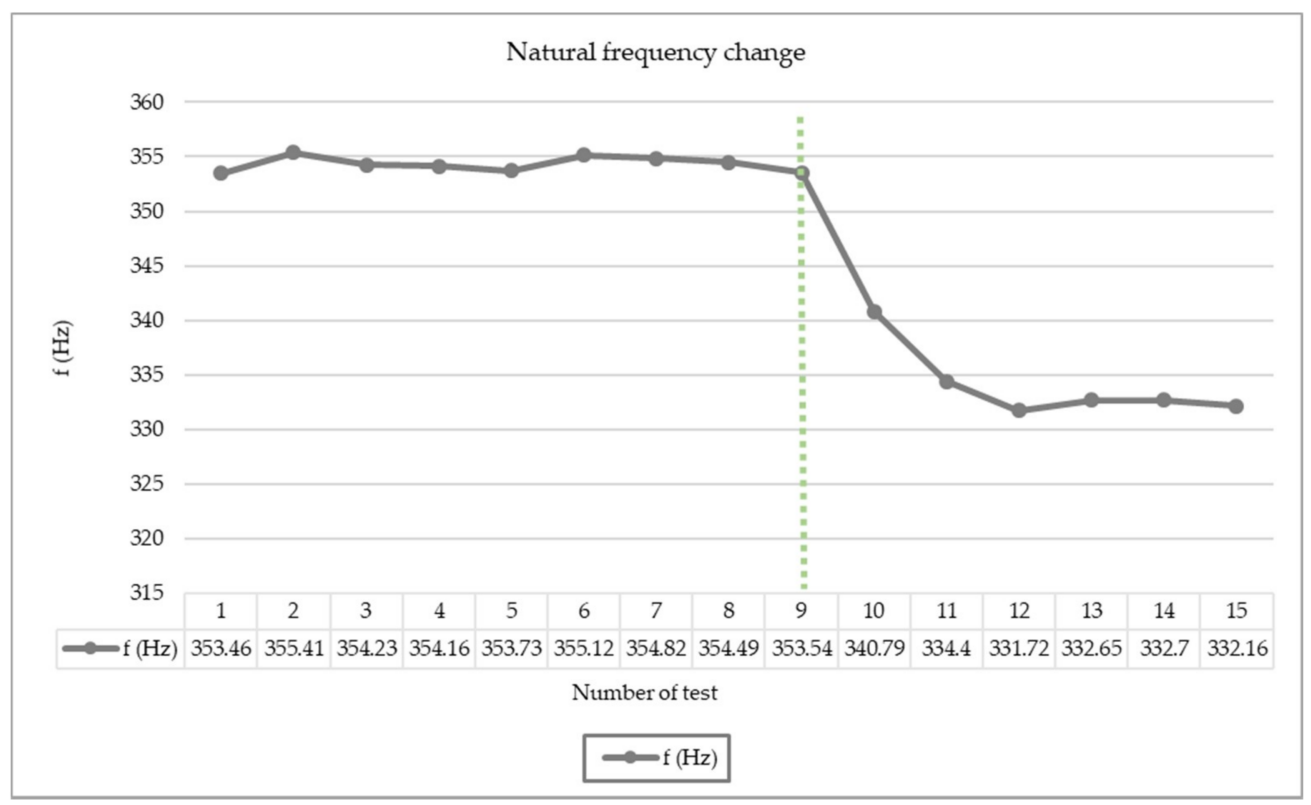

Figure 8. Change in the natural frequency values after a single test (author's processing based on [56]).

G.R. Gillich et al. [57] introduced the corrosion indicator (CI) which in mathematical form maintains changes in modal parameters depending on the position and magnitude of corrosion damage. Experimental investigations were carried out on a steel beam measuring $50 \times 5 \times 1000 \mathrm{~mm}$ with a gradual reduction of the beam cross section by $0.5 \mathrm{~mm}, 1.0 \mathrm{~mm}$, and $1.5 \mathrm{~mm}$. Modal analysis, using hexahedral finite elements, was performed in the ANSYS software program. By comparing the analytically obtained results with the results of experimental research and the results from the software program, a high concordance was shown and thus the reliability of the results in mathematical form was confirmed [57].

M. Maalej et al. [58] conducted laboratory tests in which they studied the influence of cracks, corrosion and damage repair on the frequency response of reinforced concrete beams measuring $324 \mathrm{~mm} \times 235 \mathrm{~mm} \times 2500 \mathrm{~mm}$. Concrete beams were reinforced longitudinally with two bars with a diameter of 13 and $16 \mathrm{~mm}$, and longitudinally with forks with a diameter of $6 \mathrm{~mm}$. The reinforced concrete beams were then divided into two series, series $\mathrm{O}$ (beams O1, $\mathrm{O} 2$ and O3) and series E (beams E1, E2 and E3), where in the case of beams from series $E$ the lower third of the volume of the beam was made of concrete with improved properties with glass and polyethylene fibers. Beams O1 and E1 served as control beams. Other beams went through four conditions during the test: undamaged condition $(\mathrm{H})$, condition with cracks present $(\mathrm{C})$, corroded condition $(\mathrm{CR})$, and condition after repair (R). The beams were dynamically tested after each of these conditions [58].

The performed dynamic tests in [58] showed significant changes in the value of the normalized frequency Rf according to the simulated states of reinforced concrete beams, with the changes in the series $\mathrm{O}$ beams being more prominent than the changes in the series $E$ beams. In conditions with cracks (CR) present, there was a decrease in the value of $\mathrm{Rf}$, due to the reduced contribution of the tensile zone of the beam stiffness. A significant increase (5-14\%) of the normalized frequency Rf occurred in the corroded state (CO), and it is assumed that the cause is corrosion products that increase the friction between concrete 
and steel, which leads to increased bond strength and beam stiffness. In the condition after remediation $(\mathrm{R})$, a decrease in the value of $\mathrm{Rf}$ was recorded [58].

S. Stanciu et al. [55] determined the influence of loss mass and loss stiffness on natural frequencies of corroded beam $(250 \mathrm{~mm} \times 40 \mathrm{~mm} \times 5 \mathrm{~mm})$. Applying the finite element method (FEM) and the modal analysis module, the natural frequencies were obtained in numerical approach.

The numerical analysis showed that the most sensitive modes in changing frequencies with the depth of corrosion were bending modes. Also, the first bending mode was more sensitive depending on the corroded depth than the first torsion mode $(6.9 \%$ versus $2.23 \%$ ) [59].

Y. Zhang et al. [60] presented laboratory research for analyzing the natural frequency response of the two RC beams with dimensions of $2000 \mathrm{~mm} \times 150 \mathrm{~mm} \times 50 \mathrm{~mm}$ affected by steel corrosion. After the accelerated steel corrosion test, the natural frequency, cracking area, and equivalent elastic modulus of the test beams were measured [60].

The results of the study [60] show that the variation of natural frequency could identify the corrosion damage of the steel bar even without surface cracking of the RC beam. Furthermore, the second-order frequency should be more indicative of the damage scenario. Also, the trend of the natural frequency values was consistent with the trend observed in the calculated equivalent elastic modulus values [60].

The goal of the investigation in [61] was to determine the effect of steel bar corrosion of reinforced concrete beams on the vibration frequency response. During the corrosion induced process, the beams were tested in flexure by applying a gradual load at the middle of each beam. In addition, impact load testing was performed to determine the vibration parameters. The results show a clear tendency in which stiffness parameter EI decreases, and the natural frequencies shift toward lower values as the corrosion of the embedded steel increases [61].

The study [62] presented the use of natural frequencies for the identification of damage locations in detecting the location and severity of corrosion in reinforced concrete beam models. The simply supported beam was modeled with five different corrosion factors $(8 \%$, $16 \%, 32 \%$, and $64 \%$ ). The ratio of frequency drop $\mathrm{f}_{\text {corrode/uncorrode was obtained to visualize }}$ all modes at the corroded location. The results of the frequency drop illustrate that the poorest location of corrosion was detected at $\mathrm{x} / \mathrm{L}$ between 0.4 and 0.7 . It was concluded that ratio $\mathrm{f}_{\text {corrode/uncorrode }}$ can be used to detect localized corrosion [62].

\subsection{Synthesis of Results}

A review of the observed research shows that the artificially induced corrosion of reinforcement was approximately the same in all but [56], which considered only local corrosion due to its greater similarity to corrosion on real structures. The study [51] covered both uniform and local corrosion. In studies [52,54], the corrosion caused was almost uniform, and as such was taken into account when comparing the results.

In all studies, the values of natural frequencies were determined by dynamic tests, while changes in the values of modal damping coefficients were considered in studies [51-53,55,56], and modal forms were observed only in the study [52] (Table 2).

An analysis of the literature review shows that previous research in determining corrosion on reinforced concrete elements was based on changes in basic dynamic parameters. According to previous research for crack detection (e.g., caused by bending) on structural elements, derivatives of basic dynamic parameters were shown to be more accurate. Therefore, it is assumed that it would be possible to obtain better results when determining corrosion on reinforced concrete elements with derivatives than by the use of basic dynamic parameters. 
Table 2. Review of the literature related to individual methods of determining damage.

\begin{tabular}{|c|c|c|}
\hline Category & $\begin{array}{c}\text { Determination of Corrosion in } \\
\text { Reinforced Concrete Elements Analysis } \\
\text { of Dynamic Parameters }\end{array}$ & Literature Review \\
\hline \multirow{3}{*}{$\begin{array}{l}\text { By applying basic } \\
\text { dynamic parameters }\end{array}$} & Changing the natural frequency & {$[10,50-60]$} \\
\hline & Change in damping coefficient & {$[51-53,55,56]$} \\
\hline & Changing modal shapes & [52] \\
\hline \multirow{2}{*}{$\begin{array}{l}\text { By applying deviation of } \\
\text { basic dynamic parameters }\end{array}$} & Changing the curvature of modal shapes & - \\
\hline & Changing modal flexibility & - \\
\hline
\end{tabular}

The synthesis of the results of the research with uniform corrosion of reinforced concrete beams $[10,50-54,58]$ is given in Table 3 , in which the change of natural frequencies due to corrosion was calculated according to (1). The negative values in Table 3 represent a decrease, and the positive values an increase in the amounts of natural frequencies.

Table 3. Comparison of minimum and maximum values of change of natural frequencies (\%).

\begin{tabular}{cccccccc}
\hline References & {$[10]$} & [50] & [51] & [52] & [53] & [54] & [58] \\
\hline$\delta_{\mathrm{i}, \min }[\%]$ & -5.00 & -0.10 & -0.67 & -2.34 & -3.74 & -9.00 & 5.40 \\
\hline$\delta_{\mathrm{i}, \max }[\%]$ & -20.31 & 1.41 & -2.60 & 4.29 & -5.59 & -17.00 & 14.30 \\
\hline $\begin{array}{c}\text { degree of corrosion } \\
\text { damage [\%] }\end{array}$ & $\mathrm{n} / \mathrm{a}$ & $\mathrm{n} / \mathrm{a}$ & 6.18 & 15.00 & 7.70 & 16.00 & 15.00 \\
\hline
\end{tabular}

The results in Table 3 refer to the data collected for the first four natural frequencies. The loss of steel cross section, as a degree of corrosion damage, in research [54] is 16\%, in research [52] and [58] 15\%, in research [53] 7.7\%, and in research [51] 6.18\%. A review of the results concludes that the changes in natural frequencies are significant in [10,51-54] and as such may be a relevant parameter in determining vibration-based damage. In research [50], the corrosion process in the absence of cracks in concrete did not significantly affect the dynamic response of the beam.

In studies $[52,55,58]$ there was an increase in the values of natural frequencies. The increase in value was explained by a stronger bond between the reinforcing bars and concrete due to the accumulated corrosion products in turn due to the low load level of the reinforced concrete elements. The most significant increase in the value of natural frequencies, in the amount of $16 \%$ to $24 \%$, occurred in study [55].

In the study [56] with the presence of local corrosion, there was a decrease in the value of natural frequencies in the amount of $5.8 \%$ to $33.0 \%$. These values are significant and as such can serve as a reliable parameter for determining damage. In the case of natural frequencies in the part of the research [51] related to local corrosion, the previously described phenomenon of decreasing values is present until the third repeated test, after which the values are stable.

The damping coefficient, as a parameter for determining the damage caused by reinforcement corrosion, was observed in studies [51-53,55,56]. In studies with uniform corrosion, the increase in the damping coefficient of corroded reinforced concrete elements in relation to undamaged elements was a maximum of 59.0\% [51], 76.47\% [52], 141.38\% [53], and $56.25 \%$ [55], provided that in the research [53] the stated value refers to the second modal form, because in the first modal form a decrease in the value of the damping coefficient in the amount of $47.18 \%$ was determined. In studies with local corrosion [56], the increase in modal damping values ranged from $117 \%$ to $768 \%$. In the part of the research [51], in which local corrosion was considered, the values of damping coefficients increased until the fourth repetition after which they begin to decrease. The results of these studies show that changes in the values of the damping coefficient are more significant 
than changes in the values of natural frequencies, and as such a more sensitive parameter for determining the damage caused by corrosion of reinforcement.

The change of mode shapes during corrosion damage is considered only in article [52]. Although the artificially induced corrosion in the article is almost uniform, a good agreement between the mode shapes of the undamaged and damaged condition was shown, i.e., the MAC criterion was higher than 0.95 . As this is only one study, further, extensive tests are needed to examine the potential to determine the existence and location of damage caused by corrosion of reinforcement using mode shapes, which should certainly include local corrosion.

\section{Conclusions}

Although dynamic parameters have great potential in determining corrosion damage on reinforced concrete elements, the authors concluded that this area has not been sufficiently investigated.

There are several indications that modal damping may be a more appropriate dynamic parameter than natural frequencies in determining corrosion damage, but this has only been shown in a few studies involving large dissipation of results as well as phenomena with different results on successive repeats. Also, when determining the values of natural frequencies in several studies there was a significant increase in value, especially with less loaded reinforced concrete elements, which is explained by the stronger bond between concrete and steel due to the presence of corrosion products. Such explanations are the result of the thinking and logical conclusions of individual authors, and further research should prove them experimentally. Also, only one study has substantiated the great potential for the application of mode shapes in the determination of damage caused by corrosion and in uniform corrosion. The potential shown should also be verified by further research involving local corrosion.

As can be concluded from all of the above, the potential of vibration-based methods in determining the damage caused by corrosion on reinforced concrete elements is unquestionable. Considering the number of studies conducted, this potential has not been adequately explored. As a result, there is a need for further extensive research in this area with the aim of developing a methodology for the timely detection of corrosion problems through continuous monitoring of structural systems. In this way, the risk of structural collapse, which usually leads to numerous human fatalities, may be reduced.

Through future tests it is necessary to introduce the factors of uniform and local corrosion with different losses of reinforcement cross-sectional area, with different reinforcement coefficients and boundary conditions of beams, as well as to investigate the use of mode shapes to a greater extent than present in previous research.

Author Contributions: Conceptualization, I.D. and I.K.; methodology, I.D. and M.S.; formal analysis, I.D. and I.K.; investigation, I.D. and D.D.; writing — original draft preparation, I.K.; writing-review and editing, I.D.; visualization, I.K.; supervision, D.D.; funding acquisition, I.D., D.D. and M.S. All authors have read and agreed to the published version of the manuscript.

Funding: This research was funded by the European Union through the European Regional Development Fund's Competitiveness and Cohesion Operational Program, grant number KK.01.1.1.04.0041, project "Autonomous System for Assessment and Prediction of infrastructure integrity (ASAP)." The APC was funded by the authors' affiliation.

Institutional Review Board Statement: Not applicable.

Informed Consent Statement: Not applicable.

Data Availability Statement: Not applicable.

Conflicts of Interest: The authors declare no conflict of interest. The funders had no role in the design of the study; in the collection, analyses, or interpretation of data; in the writing of the manuscript, or in the decision to publish the results. 


\section{References}

1. Morgese, M.; Ansari, F.; Domaneschi, M.; Cimellaro, G.P. Post collapse analysis of Morandi's Polcevera vidauct in Genoa Italy. J. Civ. Struct. Health Monit. 2020, 10, 69-85. [CrossRef]

2. Deng, L.; Wang, W.; Yu, Y. State-of-the-art review on the causes and mechanisms of bridge collapse. J. Perform. Constr. Facil. 2016, 30, 04015005. [CrossRef]

3. Choudhury, J.R.; Hasnat, A. Bridge collapses around the world: Causes and mechanisms. In Proceedings of the IABSE-JSCE Joint Conference on Advances in Bridge Engineering, Dhaka, Bangladesh, 21-25 August 2015; p. 34.

4. Woodward, R. Bridge Managament in Europe (BRIME)_Final Report; Transport Research Laboratory: Crowthorne, UK, 2001.

5. Calvi, G.M.; Moratti, M.; O’ Reilly, G.J.; Scattarreggia, N.; Monteiro, R.; Malomo, D.; Calvi, P.M.; Pinho, R. Once upon a time in Italy: The tale of the Morandi Bridge. Struct. Eng. Int. 2019, 29, 198-217. [CrossRef]

6. Clemente, M. Monitoring and evaluation of bridges: Lessons from the Polcevera Viaduct collapse in Italy. J. Civ. Struct. Health Monit. 2020, 10, 177-182. [CrossRef]

7. Rodriguez, J.; Ortega, L.M.; Casal, J. Load carrying capacity of concrete structures with corroded reinforcement. Constr. Build. Mater. 1997, 11, 239-248. [CrossRef]

8. Castel, A.; François, R.; Arliguie, G. Mechanical behaviour of corroded reinforced concrete beams—Part 2: Bond and notch effects. Mater. Struct. 2000, 33, 545-551. [CrossRef]

9. Fernandez, I.; Bairán, J.M.; Marí, A.R. Corrosion effects on the mechanical properties of reinforcing steel bars. Fatigue and $\sigma-\varepsilon$ behavior. Constr. Build. Mater. 2015, 101, 772-783. [CrossRef]

10. $\mathrm{Wu}, \mathrm{J} . ; \mathrm{Wu}, \mathrm{S} . \mathrm{X}$. Location of damage due to corrosion in reinforced concrete structures. In Proceedings of the 28th Conference on Our World in Concrete \& Structures, Singapore, 28-29 August 2003; pp. 595-601.

11. Wang, L.; Li, T.; Dai, L.; Chen, W.; Huang, K. Corrosion morphology and mechanical behavior of corroded prestressing strands. J. Adv. Concr. Technol. 2020, 18, 545-557. [CrossRef]

12. Ma, Y.; Peng, A.; Su, X.; Wang, L.; Zhang, J. Modeling constitutive relationship of steel bar removed from corroded PC beams after fatigue considering spatial location effect. J. Mater. Civ. Eng. 2021, 33, 04021019. [CrossRef]

13. Cornwell, P.; Farrar, C.R.; Doebling, S.W.; Sohn, H. Environmental variability of modal properties. Exp. Tech. 1999, 23, 45-48. [CrossRef]

14. Duvnjak, I. Damage Assessment on Plate Structures Using Dynamic Parameters. Ph.D. Thesis, Faculty of Civil Engineering, University of Zagreb, Zagreb, Croatia, 2015.

15. Raupach, M.; Reichling, K.; Broomfield, J.; Gulikers, J.; Schneck, U.; Serdar, M.; Pepenar, I. Inspection strategies for reinforcement corrosion surveys. Mater. Corros. 2012, 64, 111-115. [CrossRef]

16. Wang, L.; Chan, T.H. Review of vibration-based damage detection and condition assessment of bridge structures using structural health monitoring. In Proceedings of the Second Infrastructure Theme Postgraduate Conference: Rethinking Sustainable Development: Planning, Engineering, Design and Managing Urban Infrastructure, Brisbane, QLD, Australia, 26 March 2009 ; pp. $1-15$.

17. Doebling, S.W.; Farrar, C.R.; Prime, M.B. A summary review of vibration-Based damage identification methods. Shock. Vib. Dig. 1998, 30, 91-105. [CrossRef]

18. Fayyadh, M.M.; Razak, H.A. Damage identification and assessment in RC structures using vibration data: A review. J. Civ. Eng. Manag. 2013, 19, 375-386. [CrossRef]

19. Kong, X.; Cai, C.S.; Hu, J. The state-of-the-art on framework of vibration-based structural damage identification for decision making. Appl. Sci. 2017, 7, 497. [CrossRef]

20. Rytter, A. Vibrational Based Inspection of Civil Engineering Structures. Ph.D. Thesis, Department of Building Technology and Structural Engineering, Aalborg University, Aalborg, Denmark, 1993.

21. Moughty, J.J.; Casas, J.R. A state of the art review of modal-based damage detection in bridges: Development, challenges, and solution. Appl. Sci. 2017, 7, 510. [CrossRef]

22. Salawu, O.S. Detection of structural damage through changes in frequency: A review. Eng. Struct. 1997, 19, 718-723. [CrossRef]

23. Salehi, M.; Ziaeirad, S.; Ghayour, M.; Vazirizanjani, M.A. A structural damage detection technique based on measured frequency response function. Contemp. Eng. Sci. 2010, 3, 215-226.

24. Adams, R.D.; Cawley, P.; Pye, C.J.; Stone, B.J. A vibration technique for non-destructively assessing the integrity of structures. J. Mech. Eng. Sci. 1978, 20, 93-100. [CrossRef]

25. Messina, A.; Williams, E.; Contursi, T. Structural damage detection by a sensitivity and statistical-based method. J. Sound Vib. 1998, 216, 791-808. [CrossRef]

26. Shih, H.W.; Thambiratnam, D.P.; Chan, T.H. Vibration based structural damage detection in flexural members using multi criteria approach. J. Sound Vib. 2009, 323, 645-661. [CrossRef]

27. Baktiari-Nejad, F.; Esfandiari, A.; Rahai, A. Structural damage detection and assessment using measured natural frequencies. In Proceedings of the 23rd International Modal Analysis Conference, Orlando, FL, USA, 31 January-3 February 2005.

28. Jeary, A.P.; Ellis, B.R. Non-destructive in-situ testing using dynamic techniques. In Proceedings of the 3rd International Conference on Tall Buildings, Hong Kong, China, 10-15 December 1984; pp. 76-81.

29. Sohn, H.; Farrar, C.R.; Hemez, F.M.; Shunk, D.D.; Stinemates, D.W.; Nadler, B.R.; Czarnecki, J.J. A Review of Structural Health Monitoring Literature: 1996-2001; Los Alamos National Laboratories: Los Alamos, NM, USA, 2004; p. 311. 
30. Hearn, G.; Testa, R.B. Modal analysis for damage detection in structures. J. Struct. Eng. 1991, 117, 3042-3063. [CrossRef]

31. Gade, S.; Møller, N.B.; Herlufsen, H.; Konstantin-Hansen, H.; Anderson, P. Frequency domain techniques for operational modal analysis. In Proceedings of the 1st IOMAC Conference, Copenhagen, Denmark, 26-27 April 2005; pp. 261-271.

32. Wang, L. Innovative Damage Assessment of Steel Truss Bridges Using Modal Strain Energy Correlation. Ph.D. Thesis, Queensland University of Technology, Brisbane, QLD, Australia, 2012.

33. Eyre, R.; Tily, G.P. Damping measurements on steel and composite bridges. In Proceedings of the Symposium on Dynamic Behaviour of Bridges at the Transport and Road Research Laboratory, Crowthorne, UK, 19 May 1977; pp. $22-39$.

34. Whalen, T.M. The behavior of higher order mode shape derivatives in damaged, beam-like structures. J. Sound Vib. 2008, 309, 426-464. [CrossRef]

35. Fayyadh, M.M.; Razak, H.A. Detection of damage location using mode shape deviation: Numerical study. Int. J. Phys. Sci. 2011, 6, 5688-5698. [CrossRef]

36. Farrar, C.R.; James, G.H. System identification from ambient vibration measurements on a bridge. J. Sound Vib. 1997, 205, 1-18. [CrossRef]

37. Allemang, R.J.; Brown, D.L. A correlation coefficient for modal vector analysis. In Proceedings of the 1st International Modal Analysis Conference, Orlando, FL, USA, 8-10 November 1982; pp. 110-116.

38. West, M. Illustration of the use of modal assurance criterion to detect structural changes in an orbiter test specimen. In Proceedings of the Air Conference on Aircraft Structural Integrity, Palm Springs, CA, USA, 1984; pp. 1-6.

39. Kim, J.H.; Jeon, H.S.; Lee, C.W. Application of the modal assurance criteria for detecting and locating structural faults. In Proceedings of the 10th International Modal Analysis Conference, San Diego, CA, USA, 3-7 February 1992; pp. 536-540.

40. Dutta, A.; Talukdar, S. Damage detection in bridges using accurate modal parameters. Finite Elem. Anal. Des. 2004, 40, 287-304. [CrossRef]

41. Pandey, A.K.; Biswas, M.; Samman, M.M. Damage detection from changes in curvature mode shapes. J. Sound Vib. 1991, 145, 321-332. [CrossRef]

42. Maeck, J.; De Roeck, G. Damage detection on a prestressed concrete bridge and RC beams using dynamic system identification. Key Eng. Mater. 1999, 167-168, 320-327. [CrossRef]

43. Wahab, M.A.; De Roeck, G. Damage detection in bridges using modal curvatures: Application to a real damage scenario. J. Sound Vib. 1999, 226, 217-235. [CrossRef]

44. Ho, Y.K.; Ewins, D.J. On structural damage identification with mode shapes. In Proceedings of the European COST F3 Conference on System Identification \& Structural Health Monitoring, Madrid, Spain, 6-9 June 2000; pp. 677-684.

45. Farrar, C.R.; Worden, K. Structural Health Monitoring-A Machine Learning Perspective, 1st ed.; John Wiley \& Sons: Hoboken, NJ, USA, 2013.

46. Pandey, A.K.; Biswas, M. Damage detection in structures using changes in flexibility. J. Sound Vib. 1994, 169, 3-17. [CrossRef]

47. Toksoy, T.; Aktan, A. Bridge condition assessment by modal flexibility. Exp. Mech. 1994, 34, 271-278. [CrossRef]

48. Zhang, Z.; Aktan, A.E. The damage indices for constructed facilities. In Proceedings of the 13th International Modal Analysis Conference, Nashville, TN, USA, 13-16 February 1995; pp. 1520-1529.

49. Patjawit, A.; Kanok-Nukulchai, W. Health monitoring of highway bridges based on a Global Flexibility Indeks. Eng. Struct. 2005, 27, 1385-1391. [CrossRef]

50. Capozucca, R. Damage assessment in PRC and RC beams by dynamic tests. J. Phys. Conf. Ser. 2011, 305, 12098-12107. [CrossRef]

51. Shahzad, S.; Yamaguchi, H.; Takanami, R.; Asamoto, S. Detection of corrosion-induced damage in reinforced concrete beams based on structural damping identification. In Proceedings of the Thirteenth East Asia-Pacific Conference on Structural Engineering and Construction (EASEC-13), Sapporo, Japan, 11-13 September 2013; pp. G-2-4-G-2-11.

52. Zuccarino, L.; De Leonardis, A.; Di Evangelista, A.; Valente, C. Sensitivity of modal parameters for damage detection in corroded beam elements of the Pescara benchmark. J. Phys. Conf. Ser. 2011, 305, 12082-12091. [CrossRef]

53. Razak, H.A.; Choi, F.C. The effect of corrosion on the natural frequency and modal damping of reinforced concrete beams. Eng. Struct. 2001, 23, 1126-1133. [CrossRef]

54. Ortega, N.F.; Robles, S.I. Assessment of Residual Life of concrete structures affected by reinforcement corrosion. HBRC J. 2016, 12, 114-122. [CrossRef]

55. Zou, D.J.; Liu, T.J.; Qiao, G.F. Experimental investigation on the dynamic properties of RC structures affected by the reinforcement corrosion. Adv. Struct. Eng. 2014, 17, 851-860. [CrossRef]

56. Hettiarachchi, D.C.; Matsumoto, Y.; Takanami, R. Preliminary investigation of changes in damping mechanism caused by corrosion in reinforced concrete beams. In Proceedings of the 6th International Conference on Structural Engineering and Construction Management, Kandy, Sri Lanka, 11-13 December 2015; pp. 8-14.

57. Gillich, G.R.; Stanciu, E.; Korka, Z.I.; Praisach, Z.I.; Hamat, C. Assessing corrosion damage from the natural frequency change. Rom. J. Acoust. Vib. 2017, 14, 63-68.

58. Maalej, M.; Chhoa, C.Y.; Quek, S.T. Effect of cracking, corrosion and repair on the frequency response of RC beams. Constr. Build. Mater. 2010, 24, 719-731. [CrossRef]

59. Stanciu, S.; Simoiu, D.; Crâştiu, I.; Deac, S.; Oanţâ, E.N.; Bereteu, L. The effect of corrosion on the natural frequencies of beams. ITM Web Conf. 2019, 29, 02013. [CrossRef] 
60. Zhang, Y.; Cheng, Y.; Tan, G.; Lyu, X.; Sun, X.; Bai, Y.; Yang, S. Natural frequency response evaluation for RC beams affected by steel corrosion using acceleration sensors. Sensors 2020, 20, 5335. [CrossRef]

61. Torres-Acosta, A.A.; Fabela-Gallegos, M.J.; Vega, D.V.; Madrid, M.M. Vibration monitoring to detect corrosion degradation in reinforced concrete beams. In Proceedings of the CORROSION 2003, San Diego, CA, USA, 16-20 March 2003. NACE-03283.

62. Ismail, N.; Yusof, H.; Jaafar, M.F.M. The influenced of localized corrosion on the natural frequency in the reinforced concrete beam. In Proceedings of the International Civil and Infrastructure Engineering Conference CIEC 2015, Singapore, 2016 ; pp. 117-124. [CrossRef] 